\title{
ADUBAÇÃO MINERAL E ORGÂNICA DO CAFEEIRO $\left({ }^{1}\right)$
}

\author{
GENÉSIO S. CERVELLINI $\left({ }^{2,4}\right)$ e TOSHIO IGUE $\left(^{3}\right)$
}

\begin{abstract}
RESUMO
Foram plantados, em um latossolo roxo da região de Ribeirão Preto e em um podzólico vermelho-amarelo orto da de Mococa, dois experimentos com cafeeiro Bourbon Vermelho. Os tratamentos com nitrogênio, fósforo, potássio e esterco constituíram um fatorial $2^{4} \mathrm{em}$ quadrado quase latino com quatro repetições. Foram analisados os dados de produção, obtidos em três períodos de quatro anos. O efeito do esterco foi significativo nos dois solos, sendo maior no latossolo roxo, enquanto o nitrogênio, também significativo em ambos, destacou-se no podzólico vermelho-amarelo orto. O potássio apresentou pequeno efeito somente no latossolo roxo, cuja análise de terra revelou menor teor do elemento.
\end{abstract}

Termos de indexação: cafeeiro, Bourbon Vermelho, adubação mineral e orgânica.

\section{ABSTRACT \\ MINERAL AND ORGANIC FERTILIZATION OF COFFEE TREE}

The effect of manure and mineral fertilizers with nitrogen, phosphorus and potassium on coffee yield, was evaluated with a $2^{4}$ factorial experiment, Bourbon Vermelho variety, conducted on a Latosolic B "Terra Roxa" at Ribeirão Preto, and on a Red Yellow Podzolic at Mococa, State of São Paulo, Brazil regions. Twelve years of grain productions were analised in three periods of four years each. The manure effect upon coffee yield was significant on both experiments and high on the Red Latosolic Soil. Nitrogen showed high effect over the production also on both experiments and was higher on the Red Yellow Podzolic Soil. The effect of potassium was small on the Latosolic and in the Red Yellow Podzolic Soil. Potassium did not show any effect due to high level of natural potassium of the soil.

Index terms: coffee, Bourbon Vermelho, mineral fertilization, organic fertilization.

( ${ }^{1}$ ) Publicado parcialmente no 8: Congresso Brasileiro de Pesquisas Cafeeiras, realizado em Campos do Jordão (SP), em 1980. Recebido para publicação em 1 de novembro de 1993 e aceito em 9 de junho de 1994.

$\left({ }^{2}\right)$ Pesquisador Científico, Seçāo de Café, Instituto Agronômico (IAC), Caixa Postal 28, 13001-970 Campinas (SP).

$\left(^{3}\right)$ Pesquisador Científico, Seção de Técnica Experimental e Cálculo, IAC.

$\left.{ }^{4}\right)$ Com bolsa de pesquisa do CNPq. 


\section{INTRODUÇÃO}

Por volta de 1950 , havia, no Estado de São Paulo, cerca de um bilhão e meio de pés de café, a maioria dos quais em "terra velha", produzindo, em média, de seis a sete sacas de café beneficiado por hectare (Franco et al., 1960).

A recuperação da produtividade era o objetivo principal para que a cafeicultura voltasse a ser econômica e interrompesse o seu nomadismo para terras férteis, mesmo porque estas quase já inexistiam em São Paulo.

A cafeicultura dependia da coexistência com a exploração bovina, fornecedora do esterco de curral, a base da adubação. Juntamente com o esterco, aplicavam-se farinha de ossos e de sangue, escórias de Thomas e muito pouco nitrogênio e potássio minerais nas formas de salitre-do-chile e cloreto de potássio. Amaral (1925), que relatou algumas fórmulas empíricas de adubação, já incluía a aplicação de calcário em pequena quantidade para corrigir a acidez e reduzir os óxidos de alumínio e ferro.

Em 1953, Franco et al. (1960) instalaram, em Ribeirão Preto, num cafezal da variedade Típica com quarenta anos de idade e produção média dos últimos três anos de oito sacas de café beneficiado por hectare, um experimento fatorial de NPK mais tratamentos com esterco, adubação verde e micronutrientes. Obtiveram recuperação gradual da produtividade, atingindo a média de treze sacas de café beneficiado por hectare no quarto ano de aplicação.

Outros ensaios com uso de esterco, instalados na época, não tiveram a sua importância destacada devido ao grande entusiasmo provocado pelas novas orientações do cultivo do cafeeiro, recomendando fertilizantes minerais em quantidade bem mais elevada do que aquelas em uso.

Um desses experimentos, instalado em 1958 (Fraga \& Conagin, 1956; Lazzarini et al., 1967), em Ribeirão Preto, com fatorial $2^{4}$ com tratamentos de esterco, nitrogênio, fósforo e potássio, mostrou efeito significativo para o esterco e potássio sobre as produções de 1952 a 1954. Nesse período, verificou-se que o nitrogênio devia ser aplicado em parcelamento e que a ausência do potássio impossibilitou o desenvolvimento normal das plantas, o que determinou o encerramento do ensaio e a instalação de novo experimento, o qual é descrito no presente trabalho.

Os levantamentos do estado nutricional de cafezais pela análise foliar, realizados por Lott et al. (1961) e por Gallo et al. (1967, 1970), confirmaram a importância de nitrogênio, potássio, magnésio, zinco e boro para a cafeicultura, como observado no ensaio de Lazzarini et al. (1975), passando a ser recomendação de adubação para os principais tipos de solos paulistas, conforme Lazzarini et al. (1967), Moraes (1981), Instituto Brasileiro do Café (1981), Malavolta et al. (1981) e Rena et al. (1986). Uma revisão da adubação química do cafeeiro pelos maiores produtores é apresentada por Carvajal (1984), apontando que foi a partir de 1970 que o uso dos fertilizantes químicos, sobretudo os nitrogenados, aumentou consideravelmente tanto na América como na África.

Os incentivos dos grandes movimentos para o cultivo sem o uso de produtos químicos vieram valorizar os ensaios com aplicações de esterco, trazendo, em alguns casos, dados comparativos da aplicação de esterco e de fertilizantes minerais.

O objetivo deste trabalho foi verificar se o emprego dos fertilizantes minerais no cultivo do cafeeiro poderia elevar a produção e se adequadas quantidades, principalmente de nitrogenados e potássicos, substituiriam a aplicação de elevadas doses de esterco de curral.

\section{MATERIAL E MÉTODOS}

Os tratamentos com nitrogênio (N), fósforo (P), potássio (K) e esterco de curral (E) constituíram um fatorial $2^{4}$ com delineamento em quadrado quase latino com quatro repetições e fusão total da interação NPKE nas colunas e 1/4 das interações NPK, NPE, PKE e NKE nas linhas. Os canteiros eram formados por nove covas úteis, 
com espaçamento de $2,70 \times 2,50 \mathrm{~m}$, com quatro plantas por cova e separados por bordaduras comuns.

$O$ esterco foi empregado como fornecedor de nitrogênio $(0,56 \%$ de $\mathrm{N})$, fósforo $(0,21 \%$ de $\left.\mathrm{P}_{2} \mathrm{O}_{5}\right)$ e potássio $\left(0,56 \%\right.$ de $\left.\mathrm{K}_{2} \mathrm{O}\right)$ e como melhorador das propriedades físicas do solo.

Em Ribeirão Preto, o ensaio foi instalado em 1955, sobre o anterior, encerrado após a colheita de 1954, e cuja análise de solo apresentou os seguintes resultados, como média de quatro amostras: matéria orgânica $2,91 \%$; $\mathrm{pH} 5,25 ; \mathrm{PO}_{4}$ $0,41,\left(\mathrm{Ca}^{2+}+\mathrm{Mg}^{2+}\right) 3,40$, e $\mathrm{K} 0,13 \mathrm{cmol} / \mathrm{kg}$ (Fraga \& Conagin, 1956).

Em Mococa, o experimento foi plantado em 1952, segundo o fatorial $2^{4}$, idêntico ao de Ribeirão Preto em 1948, conforme relatório da Seção de Café (Lazzarini et al., 1967), em um podzólico vermelho-amarelo orto, cuja análise apresentou os resultados: matéria orgânica 1,17\%; pH 5,86; $\mathrm{PO}_{4}$ 0,14, $\left(\mathrm{Ca}^{2+}+\mathrm{Mg}^{2+}\right) 1,96$ e K $0,41 \mathrm{cmol} / \mathrm{kg}$.

Em Mococa, as quantidades de fertilizantes aplicadas anualmente, segundo os tratamentos, foram $40 \mathrm{~L}$ de esterco de curral curtido e seco, $200 \mathrm{~g}$ de sulfato de amônio, $200 \mathrm{~g}$ de farinha de ossos e $100 \mathrm{~g}$ de cloreto de potássio por cova. De 1956 em diante, as quantidades empregadas foram as seguintes: $40 \mathrm{~L}$ de esterco, $450 \mathrm{~g}$ de sulfato de amônio, em três parcelamentos de $150 \mathrm{~g}$, em outubro, janeiro e março, $200 \mathrm{~g}$ de superfosfato simples e $300 \mathrm{~g}$ de cloreto de potássio.

A partir de 1955, as adubações em Ribeirão Preto passaram a ser iguais às de Mococa, com exceção do cloreto de potássio, aplicado nas doses de 150 e $300 \mathrm{~g}$, por cova e por ano.

As colheitas das plantas úteis de cada canteiro foram efetuadas em uma ou mais vezes por ano. Retiraram-se amostras de massa conhecida para secagem e beneficiamento, obtendo-se um índice de rendimento: massa amostrada/massa beneficiada, o qual, aplicado às colheitas, forneceu a produção de café beneficiado, para cada canteiro.

Para evitar grande variabilidade dos dados, em vista das flutuações bienais da produção, normais em cafeeiros, reuniram-se os dados em perío- dos de quatro anos. Em Ribeirão Preto, devido a uma grande seca em 1963, com deficiências hídricas do solo de outubro a dezembro, não houve produção em 1964, quando foi realizada uma poda para reconstituição das plantas. Não houve, também, produção em 1965.

Em Mococa, a primeira produção foi a de 1955. Em 1966, após a colheita, as plantas sofreram uma poda para reconstituição, não havendo produção em 1967.

O cultivar plantado foi o Bourbon Vermelho em ambos os experimentos.

\section{RESULTADOS E DISCUSSÃo}

No quadro 1, encontram-se as produções anuais obtidas no latossolo roxo de Ribeirão Preto durante três quadriênios, a saber: 1956-59, 1960-63 e 1966-69.

Além do ciclo bienal do cafeeiro, que ocorre principalmente por causa do esgotamento da planta após uma alta produção, provocando, conseqüentemente, uma baixa produção no ano seguinte, fatores climáticos como geadas, secas e veranicos também proporcionam limitações na vegetação, floração e "pegamento" das flores e frutos novos (Rena et al., 1986).

No quadro 2, é apresentado o total de chuvas mensais em Ribeirão Preto no período 1955-70.

Os dados mostram-nos com bastante evidência os principais fatores indutores das variações observadas: em $1957 \mathrm{um}$ total de $1.651 \mathrm{~mm}$ de chuva, distribuído uniformemente pelo ano todo, inclusive durante o inverno, proporcionou ótimas condições para o desenvolvimento da planta, refletindo-se na produção de 1958 , acrescidos de 1.378 $\mathrm{mm}$ de chuva e com boa distribuição em setembro, outubro e novembro de 1957 , críticos em relação à abundância e pegamento da florada e pegamento e desenvolvimento dos frutos (Rena et al., 1986).

Em 1959, a produção foi bem menor, provavelmente devido ao esgotamento das plantas, porém as chuvas, iniciadas em agosto, proporcionaram condições para a boa produção de 1960. 
Quadro 1. Produções médias de quatro repetições em café beneficiado, obtidas no ensaio de adubação mineral e orgânica, em latossolo da região de Ribeirão Preto (SP), variedade Bourbon Vermelho

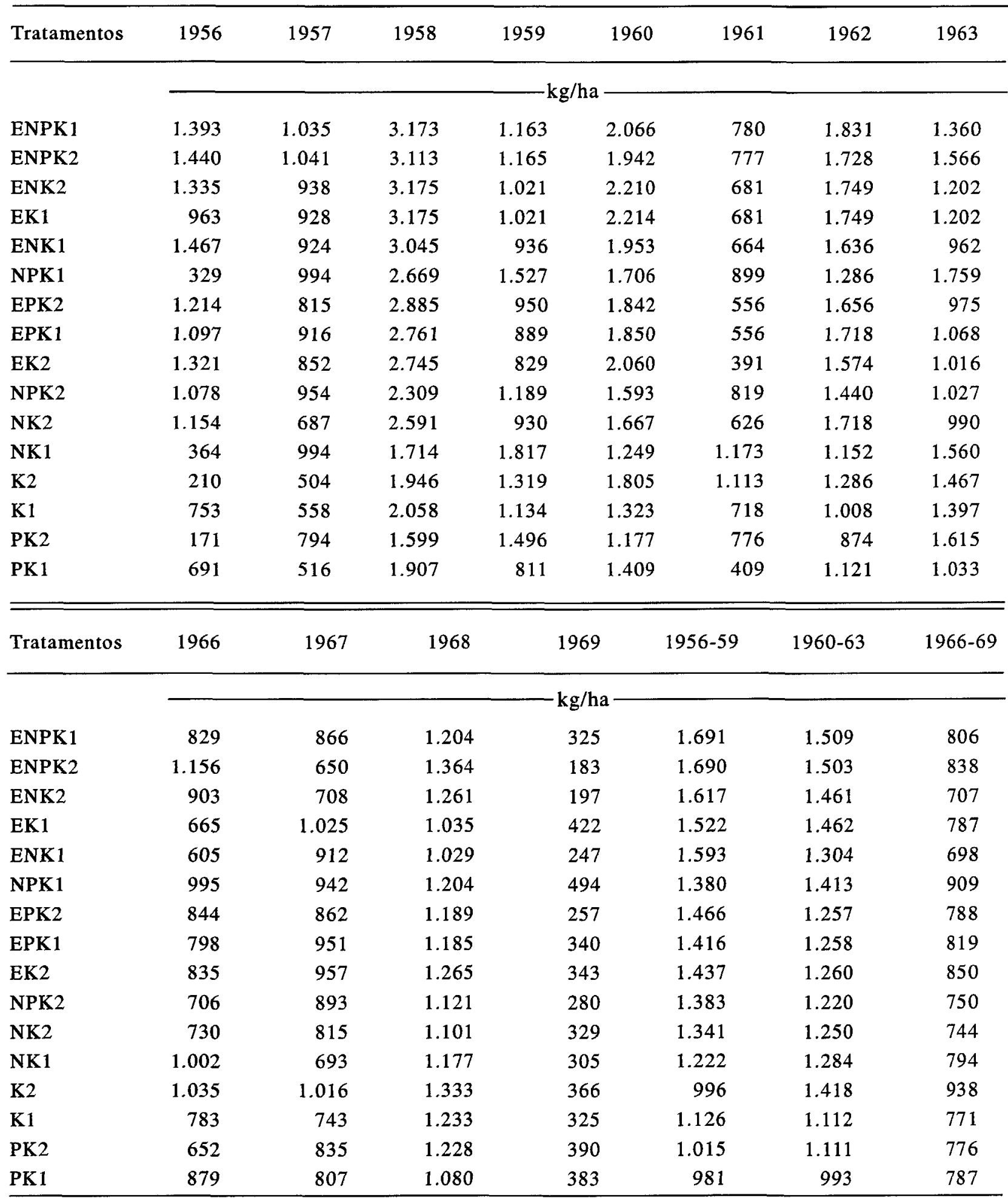


Quadro 2. Total de chuvas mensais da Estação Experimental de Ribeirão Preto ( ${ }^{1}$ )

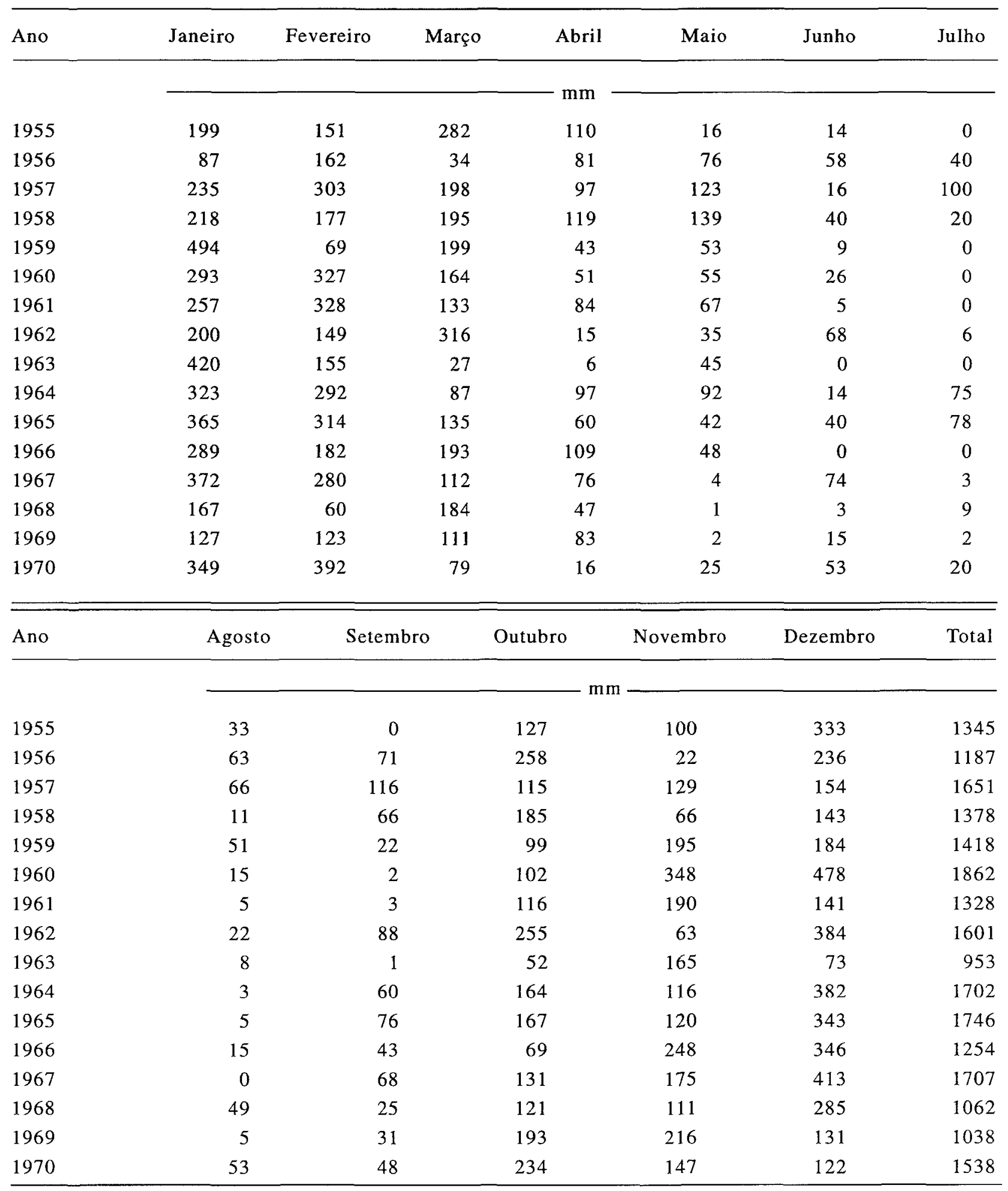

(1) Fonte: Seção de Climatologia Agrícola, IAC. 
Nesse ano, também, a abundância de chuvas a partir de outubro deu boas condições à florada e ao pegamento da colheita.

A baixa produção de 1961 deveu-se, provavelmente, ao esgotamento da planta, que nāo se recuperara inteiramente da alta produção de 1958 e de 1960. Em 1961, também ocorreu, entre junho e setembro, um período com $13 \mathrm{~mm}$ de chuva apenas, prejudicando o desenvolvimento dos ramos e, conseqüentemente, a produção do ano seguinte.

As chuvas, em 1962, de $1.601 \mathrm{~mm}$, deveriam permitir condições para boas produções em 1963, caso uma seca prolongada, desde abril até outubro, a maior de todos esses anos, não ocasionasse um esgotamento total das plantas, que foram recepadas após a colheita.

A renovação das plantas recepadas, de acordo com as produções de 1966 a 1969 , não se mostrou eficiente, provavelmente pela perda da maior parte do sistema radicular, chegando, em 1969, a produzir uma média de $324 \mathrm{~kg} / \mathrm{ha}$ em vista da baixa pluviosidade em março-setembro.

Durante os dois primeiros períodos de quatro anos, os melhores tratamentos foram os que receberam esterco e nitrogênio seguidos daqueles que receberam esterco sem nitrogênio e, só depois, os tratamentos sem esterco, mas tratados com nitrogênio e, por último, os tratamentos sem esterco e sem nitrogênio, de acordo com os quadros 1 e 3 .

A análise estatística dos quadriênios - Quadro 3 - mostra que foram significativos os efeitos do esterco e do nitrogênio nos dois primeiros quadriênios, sendo o do esterco maior. Também foi significativa a interação nitrogênio $\mathrm{x}$ fósforo nos períodos de 1965 a 1969 e de 1960 a 1963. A interação dos quatro fatores ENPK apresentou efeito significativo apenas no quadriênio 1960-63.

No último quadriênio analisado, não se observou nenhuma resposta, provavelmente devido às baixas médias de produção. Os efeitos dos tratamentos não se mostraram na mesma ordem de grandeza dos dois períodos anteriores, conforme quadros 1 e 3 . Entretanto, as produções cresceram de certa forma com variação da dose de cloreto de potássio por cova.

As maiores respostas ao potássio têm sido observadas na Colômbia, Brasil, Porto Rico, Costa do Marfim, Ruanda e algumas regiões do Quênia (Carvajal, 1984).

Quadro 3. Quadrados médios dos diferentes componentes do fatorial do ensaio de adubação mineral e orgânica em latossolo roxo da região de Ribeirão Preto (SP)

\begin{tabular}{|c|c|c|c|c|}
\hline FV & GL & $1956-59$ & $1960-63$ & $1966-69$ \\
\hline $\mathrm{E}$ & 1 & $5.276,21^{*}$ & $930,25^{*}$ & 5,64 \\
\hline $\mathrm{N}$ & 1 & $2.252,69 *$ & $630,01 *$ & 27,56 \\
\hline $\mathrm{P}$ & 1 & 15,70 & 35,01 & 23,52 \\
\hline $\mathrm{K}$ & 1 & 0,05 & 6,63 & 11,39 \\
\hline EN & 1 & 120,18 & 0,60 & 2,10 \\
\hline EP & 1 & 0,35 & 98,51 & 9,92 \\
\hline EK & 1 & 0,58 & 49,00 & 9,46 \\
\hline NP & 1 & $192,17 *$ & $520,98^{*}$ & 165,76 \\
\hline NK & 1 & 44,39 & 39,06 & 32,49 \\
\hline PK & 1 & 14,54 & 72,25 & 105,06 \\
\hline ENPK & 5 & 29,21 & $168,64^{*}$ & 23,35 \\
\hline ERRO & 35 & 36,96 & 62,61 & 40,74 \\
\hline
\end{tabular}


Quadro 4. Produções anuais de café beneficiado, média de quatro repetições, obtidas no ensaio de adubação mineral e orgânica em podzólico vermelho-amarelo orto de Mococa, variedade Bourbon Vermelho de 1955 a 1971

\begin{tabular}{|c|c|c|c|c|c|c|c|c|c|}
\hline Tratamentos & 1955 & 1956 & 1957 & 1958 & 1959 & 1960 & 1961 & 1962 & 1963 \\
\hline ENPK & 895 & 453 & 3.192 & 596 & 3.449 & 198 & 3.812 & 131 & 3.057 \\
\hline $\mathrm{EN}$ & 936 & 405 & 3.053 & 430 & 3.470 & 169 & 3.669 & 23 & 3.194 \\
\hline ENP & 726 & 342 & 3.741 & 277 & 3.720 & 107 & 3.325 & 436 & 2.368 \\
\hline NK & 888 & 426 & 3.043 & 554 & 3.440 & 200 & 3.180 & 146 & 2.481 \\
\hline ENK & 597 & 239 & 3.314 & 326 & 3.402 & 101 & 2.943 & 277 & 2.304 \\
\hline NPK & 684 & 330 & 3.045 & 473 & 3.180 & 110 & 3.147 & 169 & 2.480 \\
\hline $\mathrm{N}$ & 692 & 319 & 2.746 & 711 & 3.408 & 129 & 3.301 & 110 & 2.368 \\
\hline NP & 651 & 363 & 2.425 & 528 & 3.079 & 123 & 3.412 & 24 & 2.690 \\
\hline EPK & 670 & 298 & 2.442 & 203 & 2.119 & 77 & 1.811 & 76 & 2.309 \\
\hline EK & 809 & 425 & 3.043 & 219 & 2.197 & 81 & 1.830 & 91 & 2.250 \\
\hline EP & 693 & 427 & 2.151 & 261 & 1.846 & 73 & 1.702 & 42 & 2.211 \\
\hline E & 717 & 322 & 1.988 & 213 & 1.723 & 86 & 1.414 & 9 & 2.340 \\
\hline$P$ & 748 & 314 & 1.871 & 313 & 1.645 & 75 & 1.140 & 16 & 1.642 \\
\hline PK & 801 & 390 & 1.323 & 524 & 1.507 & 77 & 1.081 & 10 & 1.519 \\
\hline K & 678 & 378 & 1.839 & 270 & 1.323 & 56 & 788 & 4 & 1.417 \\
\hline Testemunha & 603 & 325 & 1.274 & 170 & 1.235 & 56 & 683 & 6 & 1.118 \\
\hline Tratamentos & 1965 & 1966 & 1968 & 1969 & 1970 & 1971 & $1955-60$ & $1961-66$ & 1968-71 \\
\hline ENPK & 2.214 & 1.091 & 1.189 & 1.850 & 1.792 & 2.105 & 1.566 & 2.061 & 1.734 \\
\hline EN & 1.978 & 746 & 1.390 & 1.651 & 1.700 & 1.880 & 1.500 & 1.922 & 1.655 \\
\hline ENP & 1.857 & 1.002 & 1.212 & 1.693 & 1.522 & 2.031 & 1.561 & 1.798 & 1.614 \\
\hline NK & 1.508 & 580 & 1.277 & 1.661 & 1.626 & 1.589 & 1.915 & 1.579 & 1.538 \\
\hline ENK & 2.022 & 1.103 & 1.087 & 1.520 & 1.476 & 1.614 & 1.413 & 1.730 & 1.424 \\
\hline NPK & 1.410 & 654 & 1.284 & 1.427 & 1.658 & 1.668 & 1.407 & 1.574 & 1.484 \\
\hline $\mathrm{N}$ & 1.009 & 754 & 1.441 & 1.584 & 1.457 & 1.587 & 1.432 & 1.508 & 1.517 \\
\hline NP & 865 & 674 & 1.455 & 1.540 & 1.448 & 1.323 & 1.289 & 1.535 & 1.441 \\
\hline EPK & 1.492 & 672 & 1.307 & 1.469 & 1.693 & 1.178 & 1.034 & 1.272 & 1.411 \\
\hline EK & 1.309 & 579 & 1.330 & 1.136 & 1.725 & 995 & 1.196 & 1.212 & 1.296 \\
\hline $\mathrm{EP}$ & 1.151 & 469 & 1.149 & 1.195 & 1.833 & 927 & 979 & 1.115 & 1.276 \\
\hline $\mathrm{E}$ & 1.151 & 393 & 1.249 & 1.494 & 1.628 & 1.083 & 905 & 1.061 & 1.363 \\
\hline $\mathbf{P}$ & 871 & 430 & 987 & 929 & 1.098 & 691 & 881 & 820 & 926 \\
\hline PK & 550 & 446 & 1.158 & 774 & 1.079 & 318 & 827 & 721 & 832 \\
\hline K & 429 & 375 & 782 & 616 & 810 & 320 & 786 & 586 & 632 \\
\hline Testemunha & 244 & 425 & 869 & 612 & 753 & 328 & 789 & 582 & 640 \\
\hline
\end{tabular}


As médias das produções anuais obtidas no podzólico vermelho-amarelo orto de Mococa e as médias dos períodos de 1955-60, 1961-66 e 1968-71 encontram-se no quadro 4.

O quadro 5 apresenta os totais de chuvas mensais da Estação Experimental de Mococa no período do ensaio.

As produções de 1955 e 1956 são as obtidas no terceiro e no quarto ano de plantio no campo, havendo decréscimo em 1956 devido à baixa pluviosidade de abril a setembro do ano anterior.

Em 1957, 1959 e 1963, as produções foram elevadas, tendo havido boa distribuição de chuvas a partir da primavera dos anos anteriores, proporcionando boas condições para o desenvolvimento dos ramos produtivos e, também a partir da primavera dos mesmos anos, propiciando boas condições para pegamento das flores $c$ frutos. Em 1963 ocorreu forte seca com um total de preci- pitação de $30 \mathrm{~mm}$ apenas, de abril a setembro. Em 1964 não houve produção e, provavelmente, houve grande perda do sistema radicular, que, devido às produções de 1965 e 1966, não se recuperou totalmente, evidenciando má-formação da parte aérea, que foi recepada após produção de 1966. Não houve, portanto, produção em 1967.

As produções de 1968 a 1971 foram boas, sem ser consideradas altas, eliminando o ciclo bienal, por não permitir, provavelmente, recuperação mais completa do sistema radicular, mesmo no ano agrícola de 1970-71, que apresentou chuvas abundantes. De modo geral, aparecem como melhores tratamentos os que incluem esterco e nitrogênio, seguidos daqueles com nitrogênio sem esterco e com esterco sem nitrogênio, contrariamente ao ensaio realizado no latossolo roxo e, finalmente, os tratamentos sem esterco e sem nitrogênio, conforme os quadros 4 e 6 .

Quadro 5. Totais de chuvas mensais da Estação Experimental de Mococa $\left({ }^{1}\right)$

\begin{tabular}{rrrrrrrr}
\hline Ano & Janeiro & Fevereiro & Março & Abril & Maio & Junho & Julho \\
\hline & & & & & & \\
1954 & 214 & 243 & 144 & 21 & 152 & 107 & 7 \\
1955 & 143 & 124 & 174 & 44 & 8 & 36 & 0 \\
1956 & 130 & 289 & 124 & 77 & 75 & 74 & 47 \\
1957 & 248 & 275 & 242 & 110 & 32 & 22 & 89 \\
1958 & 335 & 114 & 236 & 64 & 107 & 48 & 11 \\
1959 & 336 & 103 & 153 & 41 & 9 & 3 & 0 \\
1960 & 278 & 224 & 83 & 81 & 98 & 52 & 1 \\
1961 & 178 & 364 & 235 & 101 & 35 & 0 & 0 \\
1962 & 170 & 292 & 321 & 37 & 63 & 25 & 5 \\
1963 & 344 & 161 & 90 & 4 & 12 & 0 & 0 \\
1964 & 221 & 145 & 121 & 23 & 162 & 30 & 50 \\
1965 & 403 & 329 & 201 & 88 & 107 & 44 & 83 \\
1966 & 408 & 188 & 332 & 32 & 58 & 0 & 0 \\
1967 & 276 & 228 & 143 & 16 & 30 & 82 & 1 \\
1968 & 245 & 125 & 48 & 60 & 34 & 0 & 3 \\
1969 & 206 & 189 & 123 & 85 & 91 & 63 & 33 \\
1970 & 232 & 368 & 122 & 54 & 99 & 31 & 96 \\
1971 & 58 & 137 & 146 & 95 & 43
\end{tabular}


Quadro 5. Conclusão

\begin{tabular}{|c|c|c|c|c|c|c|}
\hline Ano & Agosto & Setembro & Outubro & Novembro & Dezembro & Total \\
\hline 1954 & 0 & 5 & 126 & 97 & 340 & 1455 \\
\hline 1955 & 22 & 2 & 122 & 132 & 331 & 1137 \\
\hline 1956 & 49 & 76 & 117 & 81 & 320 & 1457 \\
\hline 1957 & 33 & 112 & 93 & 84 & 162 & 1500 \\
\hline 1958 & 16 & 111 & 182 & 44 & 121 & 1386 \\
\hline 1959 & 32 & 39 & 71 & 210 & 174 & 1171 \\
\hline 1960 & 8 & 5 & 92 & 230 & 268 & 1419 \\
\hline 1961 & 3 & 0 & 78 & 180 & 197 & 1372 \\
\hline 1962 & 31 & 57 & 250 & 85 & 398 & 1732 \\
\hline 1963 & 14 & 0 & 55 & 132 & 68 & 881 \\
\hline 1964 & 0 & 67 & 113 & 119 & 393 & 1443 \\
\hline 1965 & 36 & 54 & 304 & 85 & 212 & 1944 \\
\hline 1966 & 16 & 45 & 147 & 222 & 441 & 1886 \\
\hline 1967 & 0 & 53 & 113 & 290 & 286 & 1517 \\
\hline 1968 & 41 & 39 & 106 & 85 & 83 & 869 \\
\hline 1969 & 16 & 19 & 133 & 249 & 244 & 1391 \\
\hline 1970 & 92 & 111 & 141 & 137 & 143 & 1526 \\
\hline 1971 & 0 & 58 & 168 & 128 & 411 & 1374 \\
\hline
\end{tabular}

(1) Fonte: Seção de Climatologia Agrícola, IAC.

A análise estatística das produções - Quadro 6 - mostra que foram significativos os efeitos do esterco e do nitrogênio nos três quadriênios analisados. O efeito da interação esterco x nitrogênio foi significativo apenas no último quadriênio.

O efeito do nitrogênio nesse solo foi mais elevado que o do esterco. A quantidade total aplicada de $80 \mathrm{~g}$ de $\mathrm{N}$ do esterco mais $90 \mathrm{~g}$ de $\mathrm{N}$ do sulfato de amônio foi baixa. As produções poderiam ter sido maiores, talvez, se as quantidades de nitrogênio fossem mais elevadas, conforme se observou mais tarde nos trabalhos de Moraes et al. (1976, 1985) e Cervellini (1986), nos quais as produções são crescentes com aplicações anuais de 180 ou $240 \mathrm{~g}$ de $\mathrm{N}$ por cova.
Por esses resultados, o esterco agiu, aparentemente, como fonte de nitrogênio complementar, aumentando o $\mathrm{N}$ disponível, que, na presença dos elevados teores de potássio do solo, produziu um efeito de interação, aumentando as produções de café. Essa observação fica reforçada quando se verifica que Cervellini et al. (1986) observaram aumentos de produção no mesmo tipo de solo, até aplicações anuais de $400 \mathrm{~kg} / \mathrm{ha}$ de $\mathrm{N}$, equivalente a $240 \mathrm{~g}$ de $\mathrm{N}$ por cova.

A planta não respondeu às aplicações anuais de potássio na quantidade de $300 \mathrm{~g}$ de cloreto de potássio, por cova, indicando que o elevado teor encontrado no solo, de $0,41 \mathrm{cmol} / \mathrm{kg}$, já era suficiente para atender às necessidades do cafeeiro, ao contrário do observado em latossolo roxo. 
Quadro 6. Quadrados médios dos diferentes componentes do fatorial do ensaio de adubação mineral e orgânica em podzólico vermelho-amarelo orto da região de Mococa (SP)

\begin{tabular}{|c|c|c|c|c|}
\hline \multirow{2}{*}{ FV } & \multirow{2}{*}{ GL } & \multicolumn{3}{|c|}{ Quadrados médios (sem confund.) dos períodos } \\
\hline & & $1955 / 1960$ & $1961 / 1966$ & 1968/1971. \\
\hline E & 1 & $299,27^{*}$ & $1865,61 *$ & $889,53 *$ \\
\hline $\mathrm{N}$ & 1 & $3331,15^{*}$ & $7022,97 *$ & $1893,34^{*}$ \\
\hline $\mathrm{EN}$ & 1 & 46,20 & 70,56 & $406,53 *$ \\
\hline $\mathrm{P}$ & 1 & 1,38 & 89,32 & 49,88 \\
\hline EP & 1 & 4,77 & 1,00 & 0,41 \\
\hline NP & 1 & 4,68 & 11,83 & 16,40 \\
\hline ENP & 1 & 60,13 & 12,71 & 23,73 \\
\hline K & 1 & 18,99 & 27,09 & 0,79 \\
\hline $\mathrm{EK}$ & 1 & 6,93 & 23,01 & 0,00 \\
\hline NK & 1 & 1,45 & 0,18 & 0,02 \\
\hline ENK & 1 & 1,38 & 10,15 & 8,46 \\
\hline $\mathrm{PK}$ & 1 & 1,13 & 18,73 & 27,83 \\
\hline EPK & 1 & 8,37 & 0,83 & 0,45 \\
\hline NPK & 1 & 72,40 & 75,27 & 0,67 \\
\hline ENPK & 1 & 18,38 & 24,91 & 0,19 \\
\hline Erro & 35 & 19,80 & 20,81 & 15,51 \\
\hline
\end{tabular}

São válidas para esse podzólico vermelho-amarelo orto as observações verificadas para o esterco quanto aos efeitos na maior estabilidade dos micronutrientes (Cervellini, 1981), principalmente para boro e zinco, comumente encontrados em teores muito baixos nos podzólicos vermelho-amarelos orto, conforme Lott et al. (1961) e Gallo et al. $(1967,1970)$.

\section{CONCLUSÕES}

1. Em Ribeirão Preto, as produções dos tratamentos aumentaram cerca de $20 \%$ quando se aplicou o esterco e foram mais acentuadas na ausência de nitrogênio. Já em Mococa, as produções se elevaram cerca de $50 \%$ pela aplicação do esterco, quando na ausência de nitrogênio.

2. Entre os nutrientes minerais, apenas o $\mathbf{N}$ proporcionou, nos dois tipos de solo, efeitos signi- ficativos na produção de café, a despeito da dose relativamente baixa.

3. O esterco propiciou acréscimo semelhante ao do $\mathrm{N}$ mineral, principalmente no solo com baixo teor de potássio.

4. Tendo em vista a baixa concentração de nutriente, mesmo de $\mathrm{N}$, conclui-se que o esterco atuou também como eficiente condicionador do solo.

\section{AGRADECIMENTOS}

Os autores agradecem e homenageiam os Pesquisadores Científicos que organizaram, coordenaram no início do projeto e colaboraram para a realização deste trabalho, a saber: Walter Lazzarini, Antonio Junqueira Reis, Tulio Ribeiro Rocha, Ferdinando Roberto Pupo de Moraes, Coaracy Moraes Franco, Mario Vieira de Moraes e Joaquim Ignácio Figueiredo. 


\section{REFERÊNCIAS BIBLIOGRÁFICAS}

AMARAL, A.P. de. Cultura prática e racional do cafeeiro. São Paulo, Monteiro Lobato, 1925. $607 \mathrm{p}$.

CARVAJAL, J.F. Cafeto, cultivo y fertilización. 2.ed. Berna, Instituto Internacional de Potassa, 1984. $254 \mathrm{p}$.

CERVELLINI, G.S. Micronutrientes na adubação do cafeeiro. In: MALAVOLTA, E.; YAMADA, T. \& GUIDOLIN, J.A., eds. Nutrição e adubação do cafeeiro. Piracicaba, Instituto da Potassa e Fosfato/Instituto Internacional de Potassa, 1981. p. $91-101$.

CERVELlinI, G.S.; TOLEDO, S.V.; REIS, A.J. \& ROCHA, T.R. Nitrogênio na adubação química do cafeeiro: doses e parcelamentos do nitrocálcio. Bragantia, Campinas, 45(1):45-55, 1986.

FrAGA, C.G. \& CONAGIN, A. Delineamento e análise de experimentos com cafeeiro. Bragantia, Campinas, 15:177-191, 1956.

FRANCO, C.M.; LAZZARINI, W.; CONAGIN, A.; REIS, A.J. \& MORAES, F.R.P. Manutenção de cafezal com adubação exclusivamente mineral. Bragantia, Campinas, 19:523-546, 1960.

GALLO, J.R.; HIROCE, R.; BATAGLIA, O.C. \& MORAES, F.R.P. Levantamento de cafezais do Estado de São Paulo pela análise química foliar. II. Solos podzolizados de Lins e Marília, latossolo roxo e podzólico vermelho-amarelo orto. Bragantia, Campinas, 29:237-248, 1970.

GALLO, J.R.; HIROCE, R.; COELHO, F.A.S. \& TOLEDO, S.V. Levantamento do estado nutricional de cafezais de São Paulo, pela análise foliar. I. Solo massapê-salmourão. Bragantia, Campinas, 26:103-117, 1967.

INSTITUTO BRASILEIRO DO CAFÉ. Cultura de café no Brasil. 4.ed. Rio de Janeiro, IBC, 1981. $503 \mathrm{p}$.

LAZZARINI, W.; MORAES, F.R.P.; CERVELLINI, G.S.; TOLEDO, S.V.; FIGUEIREDO, J.I.; REIS, A.J.; CONAGIN, A. \& FRANCO, C.M. Cultivo de café em latossolo vermelho-amarelo da região de Batatais (SP). Bragantia, Campinas, 34:229239,1975 .
LAZZARINI, W.; MORAES, F.R.P.; MORAES, M.V.; TOLEDO, S.V. \& FIGUEIREDO, J.I. Ensaios de adubação: comunicado sobre novos conceitos de fertilização do cafeeiro, emitido a 15 de abril de 1958. In: LAZZARINI, W.; MORAES, F.R.P.; MORAES, M.V.; TOLEDO, S.V. \& FIGUEIREDO, J.I. Experimentação cafeeira: 1929-1963. Campinas, Instituto Agronômico, 1967. p.134-135.

LAZZARINI, W.; MORAES, F.R.P.; MORAES, M.V.; TOLEDO, S.V. \& FIGUEIREDO, J.I. Experimentação cafeeira: 1929-1963. Campinas, Instituto Agronômico, 1967. 396p.

LOTT, W.L.; McCLUNG, A.C.; VITA, R. \& GALLO, J.R. Levantamento de cafezais em São Paulo e Paraná pela análise foliar. São Paulo, IBEC Research Institute, 1961. 69p. (Boletim 26)

MALAVOLTA, E. Nutrição mineral e adubação do cafeeiro: passado, presente e perspectivas. In: MALAVOLTA, E.; YAMADA, T. \& GUIDOLIN, J.A., eds. Nutrição e adubação do cafeeiro. Piracicaba, Instituto de Potassa e Fosfato/Instituto Internacional de Potassa, 1981. p.138-195.

MORAES, F.R.P. Adubação do cafeeiro: macronutrientes e adubação orgânica. In: MALAVOLTA, E.; YAMADA, T. \& GUIDOLIN, J.A., eds. $\mathrm{Nu}$ trição e adubação do cafeeiro. Piracicaba, Instituto da Potassa e Fosfato/Instituto Internacional de Potassa, 1981. p.77-89.

MORAES, F.R.P.; LAZZARINI, W.; CERVELLINI, G.S.; TOLEDO, S.V.; MORAES, M.V. de; REIS, A.J.; ROCHA, T.R. \& CONAGIN, A. Fontes e doses de nitrogênio na adubação química do cafeeiro em latossolo roxo e podzólico vermelho-amarelo orto. Bragantia, Campinas, 44(1):1-15, 1985.

MORAES, F.R.P.; LAZZARINI, W.; TOLEDO, S.V.; CERVELLINI, G.S. \& FUJIWARA, M. Fontes e doses de nitrogênio na adubação química do cafeciro. I. Latossolo roxo transição para latossolo vermelho-amarelo, orto. Bragantia, Campinas, 35:65-67, 1976.

RENA, A.B. \& MAESTRI, M. Fisiologia do cafeeiro. In: RENA, A.B. \& MAESTRI, M., eds. Cultura do cafeeiro. Piracicaba, Associação Brasileira para Pesquisa da Potassa c Fosfato, 1986. p.14-85. 